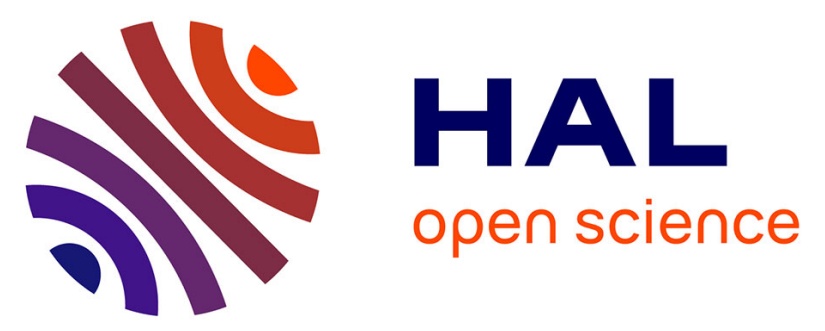

\title{
Effects of Ageing on the Bond Properties of Carbon Fiber Reinforced Polymer/Concrete Adhesive Joints: Investigation Using a Modified Double Shear Test
}

\author{
Marc Quiertant, Karim Benzarti, Julien Schneider, Fabrice Landrin, Mathieu
} Landrin, Frédéric Boinski

\section{To cite this version:}

Marc Quiertant, Karim Benzarti, Julien Schneider, Fabrice Landrin, Mathieu Landrin, et al.. Effects of Ageing on the Bond Properties of Carbon Fiber Reinforced Polymer/Concrete Adhesive Joints: Investigation Using a Modified Double Shear Test. Journal of Testing and Evaluation, 2017, 45 (6), 10.1520/JTE20160587 . hal-01569451

\section{HAL Id: hal-01569451 \\ https://hal.science/hal-01569451}

Submitted on 26 Jul 2017

HAL is a multi-disciplinary open access archive for the deposit and dissemination of scientific research documents, whether they are published or not. The documents may come from teaching and research institutions in France or abroad, or from public or private research centers.
L'archive ouverte pluridisciplinaire HAL, est destinée au dépôt et à la diffusion de documents scientifiques de niveau recherche, publiés ou non, émanant des établissements d'enseignement et de recherche français ou étrangers, des laboratoires publics ou privés. 


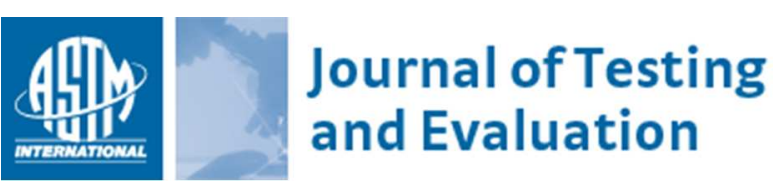

\section{Effect of ageing on the bond properties of CFRP/Concrete adhesive joints: investigation using a modified double shear test}

\begin{tabular}{|r|l|}
\hline Journal: & Journal of Testing and Evaluation \\
\hline Manuscript ID & JTE-2016-0587.R1 \\
\hline Manuscript Type: & Technical Manuscript \\
\hline Date Submitted by the Author: & n/a \\
\hline Complete List of Authors: & $\begin{array}{l}\text { Quiertant, Marc; IFSTTAR, } \\
\text { Benzarti, Karim; IFSTTAR } \\
\text { Schneider, Julien; cerema direction territoriale Ile-de-France } \\
\text { Landrin, Fabrice; cerema direction territoriale Ile-de-France } \\
\text { Landrin, Mathieu; cerema direction territoriale Ile-de-France } \\
\text { Boinski, Frédéric; cerema direction territoriale Ile-de-France }\end{array}$ \\
\hline ASTM Committees and & $\begin{array}{l}\text { D04.20 Mechanical Tests of Bituminous Mixtures < D04 ommittee on Road } \\
\text { and Paving Materials }\end{array}$ \\
\hline Subcommittees: & \begin{tabular}{l} 
CFRP, hydrothermal ageing, epoxy, shear test \\
\hline
\end{tabular} \\
\hline
\end{tabular}




\title{
Effects of ageing on the bond properties of carbon fiber reinforced
} polymer /concrete adhesive joints: investigation using a modified

\section{double shear test}

\author{
Marc Quiertant, Karim Benzarti \\ Université Paris-Est, IFSTTAR, Département Matériaux et Structures, France \\ marc.quiertant@ifsttar.fr (Corresponding author) \\ karim.benzarti@ifsttar.fr \\ Julien Schneider, Fabrice Landrin, Mathieu Landrin, Frédéric Boinski \\ CEREMA - DT Id/LEM/UCMA, France \\ julien.schneider@cerema.fr \\ fabrice.landrin@cerema.fr \\ mathieu.landrin@cerema.fr \\ Frederic.BOINSKI@concrete-mail.com
}

\begin{abstract}
Although externally bonded carbon Fiber Reinforced Polymer (FRP) composites are now commonly used for the strengthening and repair of reinforced concrete structures, the durability of the adhesive bond at the concrete/composite interface is still a matter of investigation and remains a critical issue to be addressed in order to assess the long-term performance of FRP strengthening methods. The proposed paper aims at presenting the results of an investigation on the time evolution of the adhesive bond strength of concrete/composite assemblies exposed to accelerated ageing. Such an evolution was studied by performing double lap shear tests at several intermediate periods of ageing up to 1 year, while changes in the mechanical properties of the weakest constitutive materials, namely polymer adhesive and concrete, were investigated by means of tensile and compressive tests respectively. Considering that an increase in the transfer length of aged samples can counterbalance the ageing-induced degradation of the mechanical properties of the bulk adhesive and can finally lead to an unchanged shear capacity of the joint, a new geometry of double-shear test specimens is proposed. This geometry involves a smaller bonded length and consequently restricts the possible increase in transfer length during ageing. Moreover, their reduced size allows the storage of a large number of samples in standard climatic chambers. A specific anchorage device was designed, so that double lap shear tests could be carried out
\end{abstract}


using a conventional universal testing machine. The obtained results show that the shear tests based on this original setup are able to reveal the evolutions of both the bond strength and the failure mode of concrete/composite assemblies subjected to various accelerated ageing conditions. Ageing conditions were found to have only slight detrimental effects on the mechanical characteristics of samples, and finally a partial recovery was observed.

Keywords CFRP, epoxy, hydrothermal ageing, shear test.

\section{Introduction}

The effectiveness of field externally bonded Fiber Reinforced Polymers (FRPs) for the strengthening and repair of Reinforced Concrete (RC) structures has been widely demonstrated and is now worldwide accepted [1-5]. However, the durability of the adhesive bond at the concrete/FRP interface is still a matter of investigation and remains a critical issue to be addressed in order to assess the long-term performance of FRP strengthening methods [6-11].

The purpose of this paper is to present the results of a 12-month experimental investigation on the environmental durability of the concrete/carbon FRP (CFRP) adhesive bond conducted (preliminary results were also reported in [12]. Since some detrimental effects of moisture on the mechanical properties of FRP/concrete assemblies have been reported, especially with the use of cold-curing epoxy adhesives $[11,13,14]$, and since the rate of moisture diffusion increases with temperature, hygrothermal ageing conditions are considered in the present study. Moreover, as underlined by Yun and Wu [15], the durability of FRP/concrete joints under freezethaw cycling has received insufficient attention, and contradictory results were reported by different authors. On the one hand, a decrease in residual strength as a function of the number of cycles was observed by many authors [16-18], which is consistent with the fact that constituents of the joint (FRP, adhesive and concrete) exhibit different thermal expansion behaviors. On the other hand, several studies [19-23] reported a preservation, and sometimes an increase in bond strength after freeze-thaw cycling. Thus, freeze-thaw conditions are also considered in the present durability study. The evolution of the mechanical properties of the bulk adhesive and concrete are investigated through tensile and compressive tests respectively, and the time evolution of the adhesive bond strength is studied through characterization with double lap shear tests. 


\section{Experimental program}

To investigate the effects of accelerated ageing on the adhesive bond between concrete substrate and externally bonded Carbon FRP (CFRP) plates, specific shear test specimens were first designed. Then 84 of such specimens were constructed, exposed to various environments and finally tested. Double shear test experiments were periodically carried out over a period of 1 year, to monitor the bond strength of aged specimens. The evolutions of the concrete compressive strength and the tensile strength of the bulk polymer adhesive were also monitored over time. The durability of the pultruded CFRP plate was not investigated here, as this material is supposed to be not significantly affected by environmental ageing conditions [10]. 


\subsection{Double shear test experiments}

\subsubsection{Principle of the double-shear test}

In FRP strengthened RC beams, the load between FRP plate and concrete substrate is primarily transferred through interfacial shear stresses. Then, simplified shear tests are usually considered suitable to assess the bond strength of concrete-FRP interfaces [26]. In the experimental program described in this paper, double shear test experiments were carried out. Test specimens are composed of two concrete blocks attached by two parallel bonded FRP plates (Fig. 1.a). A load applied $(F)$ to the concrete blocks produces a shear stress along the adhesive joint (Fig. 1.b). Each lap joint is then submitted to the average shear stress ( $\tau_{\text {ave }}$ ), which can be calculated according to:

$$
\tau_{a v e}=\frac{F}{2 A_{a d h}}(\mathrm{MPa})
$$

where $A_{\text {adh }}$ is the bonded area of each lap joint [27].

It will be discussed later in this paper that the concrete prisms used in the present study are smaller than those commonly used for double lap shear tests (see for example the standard test proposed by the Japanese Concrete Institute in [28]). Since a realistic concrete mixture was adopted, based on a maximum gravel size of $20 \mathrm{~mm}$, it was not possible to embed a steel rod in the concrete without weakening the prisms. Such embedded steel rods are usually used to transmit the load from the universal testing machine to the concrete prisms, but preliminary tests showed that this type of fixture led to the systematic failure of the concrete prisms in our case, as illustrated in Fig. 2. Consequently, alternative fixture devices were designed. One of the two devices is shown in Fig. 3, whereas the overall shear test setup is presented in Fig. 4.

\subsubsection{Double-shear test specimens}

As reported by Aydin, Gravina, and Visintin [29], and previously underlined in the introduction section, several researchers have observed changes in the effective transfer length of FRP after ageing. Moreover, in Benzarti et al. [9] it was also noticed that, in the condition of the study, this phenomenon was accompanied by a roughly 
constant value of the shear capacity (and thus of the average shear stress) of aged samples, even though an evolution of their failure modes was observed and decreases in the Young's modulus and tensile strength of the bulk adhesive were obtained. To explain their results, these authors analyzed the strain profiles along the lap joint (as measured by strain gages stuck at the surface of the CFRP plates) and they concluded that the ageinginduced degradation of the polymer properties was counterbalanced by a redistribution of the shear load transfer along the bonded interface (i.e., a large increase in the effective transfer length), resulting in unchanged shear capacity of the joint. In this case, the shear test potentially lose its effectiveness to detect degradation of the adhesive. To overcome this difficulty in the present study, it was decided to lower the bonded length of the CFRP plates for the double shear specimens. Moreover, the reduced size of the test specimens allows storing a large number of samples in standard climatic chamber.

In a preliminary step, relying on the characterization of different specimen geometries, the design of the double shear specimens was optimized. The best configuration was defined as the geometry providing the lowest standard deviation (calculated on a series of six tests). Another important criterion of acceptability was the failure mode, which had to be a cohesive shear failure in the concrete just underneath the adhesive joint. Any other failure mode was rejected (Fig. 2). Finally the best configuration consisted of two concrete blocks of dimensions $80 \times 80 \times 150 \mathrm{~mm}^{3}$ (see Fig. 6) connected together (with a separating gap of 35mm) by two CFRP plates symmetrically bonded to the lateral faces.

Considering that most experimental campaigns based on shear test report that the concrete layer near the bonded surface is the weakest part of the joint before ageing (cohesive failure in concrete is the usual failure mode), it is then difficult to observe the ageing-induced evolution of the shear capacity of the bonded joint if the FRP system is bonded on a low grade concrete. Therefore in this study, it was decided to use high strength concrete to lower the ageing time necessary to sufficiently alter the adhesive layer to change the failure mode and shear capacity. The same concrete mixture was used to cast the concrete blocks devoted to the preliminary tests (in order to determine the best specimen geometry) as well as the blocks used in the durability study. All these concrete prisms were prepared using type I Portland cement, water, sand and gravel with respective mass ratios (with reference to the weight of cement) of 1.0:0.55:2.48:2.74. Maximum gravel size was $2 \mathrm{~cm}$. At 28 days of age, the mean cylinder compressive strength of the concrete was $63.6 \mathrm{MPa}$. 
Commercially available pultruded CFRP plates [30] and a bi-component low temperature curing epoxy adhesive [31] were used to prepare the specimens. This system (FRP and adhesive) is commonly used in the field for the strengthening of civil structures by externally bonded CFRP plates. Before performing any bonding operations, the laboratory staff received a one-day training period, provided by technical experts from SIKA France. The main mechanical properties of the strengthening system and its components (FRP and adhesive) are reported in the Technical Data Sheets provided by SIKA [30-31] and in the technical approval document published by the French approval center [32]. Only the formed sides of the concrete prisms were used to bond the CFRP plates. As prescribed in the technical data sheet, the concrete substrate was previously ground and vacuum-cleaned before the application of a thin (approximately $1.5 \mathrm{~mm}$ ) uniform layer of epoxy adhesive. A similar layer of adhesive was also applied on the surface of the CFRP plate. No primer was used in accordance with the manufacturer's application guidelines. Then each plate was positioned on the concrete surface and rolled, using a paint roller, to push out all air bubbles. To avoid premature corner failure of the concrete blocks [33], plates were bonded with a gap of $30 \mathrm{~mm}$ starting from the edge of each block. The bonding of the second plate on each specimen was achieved one day after the bonding of the first plate. The surface area of each of the four bonded joints was $70 \times 50 \mathrm{~mm}^{2}$. It is to note that the $7 \mathrm{~cm}$ bonded length cannot provide the full capacity of the system, considering that the anchorage length of such systems was measured to be approximately $10 \mathrm{~cm}$ in a previous study [34]. The geometry of the FRP-strengthened concrete specimens is presented on Fig. 6.

Finally, 168 concrete prisms of dimensions $80 \times 80 \times 150 \mathrm{~mm}^{3}$ and 28 concrete cylinders were cast respectively for the construction of 84 double-shear test specimens and for the measurement of concrete strength at selected stages of ageing (Fig. 5).

The epoxy adhesive was cured at ambient temperature for at least 3 weeks before the beginning of the durability study (i.e. before initial mechanical characterization of unaged specimens and beginning of the exposure of the other specimens to the various ageing conditions). 


\subsection{Ageing conditions}

All specimens (FRP-strengthened concrete, concrete cylinders and polymer samples) were exposed to three different hygrothermal conditions in various climatic chambers (Fig. 7). These environments consisted of:

- A constant relative humidity (RH) of $95 \%$ at a temperature of $40^{\circ} \mathrm{C}$ (climatic chamber $\mathrm{N}^{\circ} 1$ : CC1)

- Cycles of temperature, with temperature varying between $-10^{\circ} \mathrm{C}$ and $+20^{\circ} \mathrm{C}$ (see Fig. 9.a), without humidity control (climatic chamber $\mathrm{N}^{\circ} 2$ : $\left.\mathrm{CC} 2\right)$;

- Cycles of relative humidity, with relative humidity varying between $15 \%$ and $95 \%$ at a constant temperature of $40^{\circ} \mathrm{C}$ (see Fig. 9.b; climatic chamber $\mathrm{N}^{\circ} 3$ : CC3).

These ageing conditions were chosen considering that i) the water absorbed by the epoxy adhesive may affect the mechanical performance of the $\mathrm{CFRP} /$ concrete adhesive bond, that ii) the chosen temperature of $40^{\circ} \mathrm{C}$ accelerates water sorption kinetics, while remaining below the glass transition temperature of the epoxy adhesive, and that iii) exposure to subzero temperatures and freeze-thaw cycles may also contribute to a degradation of the bond properties.

The climatic chambers were controlled in temperature and humidity, using the dedicated software provided by the manufacturer, and the daily thermal cycles described in Fig. 9 were continuously run during one year. Samples were removed periodically from the various climatic chambers and the evolutions of their bond properties were investigated over the 12-month period of study. The experimental program is summarized in Table 1. 


\section{Experimental results}

In this section, the effects of ageing conditions on the property evolutions of polymer and concrete, considered in this study to be the two weakest constituents of the FRP-strengthened concrete specimens, are first investigated. Then, the second part of the section focuses on the evolutions of the FRP-concrete bond properties when subjected to the same environments.

\subsection{Evolution of concrete and adhesive}

The evolutions of constitutive material properties were determined by testing four concrete cylinders and six dumbbell shaped adhesive specimens at each scheduled time period and for each type of ageing condition. The results of these characterizations over the 12-month ageing period are presented in Fig. 10 and Fig. 11. To simplify the analysis, all the values presented in the following figures and related to aged specimens (except for Fig. 10) are normalized with respect to corresponding control values (related to unaged specimens). Error bars are plotted based on standard deviations calculated for each series of samples. The stages of ageing under consideration are 0,6 and 12 months for the measurement of compressive strength while tensile tests on epoxy specimens were performed after $0,2,4,8$ and 12 months. The initial time ( 0 month) corresponds to the moment when the samples are first exposed to the chosen environmental conditions. It also refers to 28 days after casting for the concrete cylinders and three weeks after fabrication for the bulk adhesive samples. The three week period of cure of the epoxy was chosen considering that the technical data sheet still reports slight changes in its mechanical properties after a curing period of 7-14 days at room temperature. Both concrete and adhesive samples were cured in laboratory conditions $\left(21 \pm 2^{\circ} \mathrm{C}, 50 \% \mathrm{RH}\right)$.

In view of the three available ageing stages ( $0 ; 6$ and 12 months),the property evolution of the concrete can only be discussed considering two ageing periods ( 0 to 6 months and 6 to 12 months). As a first result, it appears that concrete strength increases, whatever the ageing conditions, during the initial period of ageing and then slightly degrades (for CC2 and CC3 storage conditions) or slightly continues to increase for samples stored in CC1. 
The continuous strength development observed for concrete stored in $\mathrm{CC} 1$ is an expected trend due to the ageing condition that offers adequate amount of moisture for a continuous hydration process. In the second period of ageing in $\mathrm{CC} 2$, it is believed that freeze-thaw cycling damages the concrete, leading to a reduction in tensile strength. However, no clear explanation is proposed for the strength reduction of concrete during the second period of storage in $\mathrm{CC} 3$. Considering that the most commonly reported failure mode encountered in adhesive bond tests is concrete delamination, these results are of significant interest.

After analyzing the results presented in Fig. 11, it was observed that time evolution of the tensile strength of epoxy specimens stored in $\mathrm{CC} 2$ and $\mathrm{CC} 3$ remains roughly unchanged over the 12-month ageing period, although there is some scatter in the data. However, epoxy samples exposed to the high and constant relative humidity condition of $\mathrm{CC} 1$ exhibit rapid strength degradation over the first 2 months. After this period of 2 months, their tensile strength slightly but continuously re-increase.

To investigate the possible correlation between tensile strength evolutions and moisture absorptions, fifteen dumbbell shaped adhesive samples were specially fabricated to investigate the moisture uptake under ageing conditions. All these bulk specimens were weighed before being stored in climatic chambers. Five samples were placed in each chamber. Then, polymer samples were periodically weighed, and the moisture uptake of a specimen $i$ at the time $t$ was calculated using:

$M_{t}^{i}=\left(\frac{w_{t}^{i}-w_{0}^{i}}{w_{0}^{i}}\right) \times 100$

where:

$w_{0}^{i}$ is the weight of the sample $i$ before ageing

$w_{t}^{i}$ is the weight of the sample $i$ at the time $t$

The time evolutions of the moisture uptake of the adhesive exposed to the three studied ageing conditions are shown in Fig. 12. As expected, the higher moisture uptake was evidenced for specimens submitted to the ageing condition provided by $\mathrm{CC} 1$. These samples reach a saturation state with maximum moisture uptake around $1 \%$ after 150 days of exposure. Surprisingly, the storage condition in CC2 produced a weight loss, but recorded changes are very low. With regard to $\mathrm{CC} 3$ condition, the moisture absorption of samples reaches an asymptotic 
level of approximately $0.2 \%$ after 6 months. However, it can be considered that the mass of bulk samples stored in $\mathrm{CC} 2$ and $\mathrm{CC} 3$ remained roughly unchanged over the 12-month ageing period compared to the changes observed for samples exposed in $\mathrm{CC} 1$.

By comparing curves presented in Fig. 11 and Fig. 12, similar trends are observed, in particular globally unchanged tensile strength and moisture uptake for samples stored in $\mathrm{CC} 2$ and $\mathrm{CC} 3$ and a two period behavior of CC1 samples (first period with weight gain and tensile strength loss followed by a second period characterized by weight loss and partial recovery of tensile strength). Even if the phase of weight gain is longer than the phase of tensile strength loss, respectively 2 and 6 months, it is believed that the two phenomena are strongly linked, as already observed in many publications (for example [35]). When water alters the mechanical properties of the polymer in a reversible manner, it is usually attributed to a plasticization of the polymer network by water molecules [36-37].

These results are in line with those reported by Benzarti et al. in [9]. These authors showed that polymer samples exposed to ageing conditions similar to those in $\mathrm{CC} 1$ (moisture saturated air, temperature of $40^{\circ} \mathrm{C}$ ) are subjected to 2 antagonistic phenomena:

- a plasticization effect by water, related to the breakage of physical interactions, leading both to a decrease in the mechanical properties (tensile strength and Young's modulus) and in the glass transition temperature ( $\mathrm{Tg})$ of the polymer.

- a crosslinking effect, related to the reaction of residual monomers, which is favored by both the temperature of $40^{\circ} \mathrm{C}$ and the increased molecular mobility due to plasticization. This mechanism has opposite effects, with increases in both mechanical properties and $\mathrm{Tg}$.

In the present study, plasticization seems to be the predominant mechanism during the first stage of ageing in $\mathrm{CC} 1$ (0-2 months), as the sorption kinetics is high during this period (Fig. 12). Then, after water saturation of the polymer, crosslinking becomes progressively predominant, and leads ultimately to a partial recovery of the tensile strength. 


\subsection{Evolution of FRP-concrete bond failure}

The evolutions of the average shear strength of aged specimens are illustrated in Fig. 13 for each environmental conditions considered in this study. As a first result, it can be noticed that there is a large dispersion of experimental average bond strength values especially for samples stored in CC1. However, whatever the ageing condition, it is possible to observe a slight decrease in the average shear strength during the early period of exposure (in respectively the first 8 months for samples stored in $\mathrm{CC} 1$ and the first 2 months for samples stored in $\mathrm{CC} 2$ or in CC3). During the early period, cyclic exposure conditions in $\mathrm{CC} 2$ and $\mathrm{CC} 3$ induce very similar effects, when exposure in $\mathrm{CC} 1\left(40^{\circ} \mathrm{C}\right.$ and $95 \%$ R.H. $)$ produces a more significant degradation of the bond properties. After this first period, all the bond strength curves showed an increase, and at the end of the 12month exposure time, bond strength capacities were approximately restored up to $89 \%, 88 \%$ and $86 \%$ for samples stored in $\mathrm{CC} 1, \mathrm{CC} 2$ and $\mathrm{CC} 3$ respectively.

Moreover, a careful observation of the fractured surfaces indicated an evolution of the shear failure mode of specimens after ageing, whatever the type of environment. To analyse more precisely this phenomenon, each fracture pattern was observed considering five types of failure: cohesive failure in concrete, adhesive failure at the epoxy/concrete interface, cohesive failure in the epoxy layer, adhesive failure at the epoxy/FRP interface and interlaminar failure within the FRP. The surface areas of failure bond were visually evaluated and quantified (see for example Fig. 14 and Fig. 15). Results of these observations are shown in Fig. 16, Fig. 17 and Fig. 18 for fracture patterns of samples exposed to environmental conditions of $\mathrm{CC} 1, \mathrm{CC} 2$ and $\mathrm{CC} 3$ respectively.

From the observation of fractured surfaces, it appears that the initial failure mode was mostly mixed failure (see T0 in Fig. 16 and Fig. 17) and shifted to concrete failure after ageing in $\mathrm{CC} 2$ and $\mathrm{CC} 3$. With respect to the positive evolution of the concrete properties over ageing (Fig. 10), these results seem to indicate that the bond properties of the adhesive are not significantly altered by ageing in $\mathrm{CC} 2$ and $\mathrm{CC} 3$. This conclusion is corroborated by the mostly unchanged tensile strength of the bulk epoxy specimens exposed to the same ageing conditions. It can also be suspected that the ageing conditions in $\mathrm{CC} 2$ and $\mathrm{CC} 3$ are detrimental to the external layers of the concrete prisms, while having no significant effect on bulk concrete in the core of the concrete cylinders, (which represents a relatively high volume). 
As previously discussed, the bulk epoxy samples stored in $\mathrm{CC} 1$ are the only ones exhibiting a significant loss of tensile strength associated with a moisture induced plasticization, over the first months of ageing. This is consistent with the decrease in the shear capacity of the joint observed for CFRP/concrete assemblies exposed to $\mathrm{CC} 1$ conditions. As stated previously in section 3.1, the crosslinking mechanism of the polymer adhesive becomes more predominant over plasticization as the sorption process reaches saturation, which may explain the partial recovery of the shear strength of the bonded joints on the long term. However, due to all these mechanisms, no predominant mode of failure is observed (see Fig. 16). It is also believed that the external layers of the concrete prisms of the FRP-strengthened concrete specimens are not significantly affected by the conditions provided by $\mathrm{CC} 1$, contrary to the surface damage suspected for the concrete prisms stored in $\mathrm{CC} 2$ and CC3. Concrete failure is then rarely observed for FRP-strengthened concrete specimens under ageing conditions provided by $\mathrm{CC} 1$.

\section{Conclusions}

The results of an experimental study on the degradation of the adhesive bond between CFRP plates and concrete under accelerated ageing conditions are presented. Test specimens were exposed to various ageing conditions, i.e. saturated moist air at $95 \% \mathrm{RH}$, hygric cycles and freeze-thaw cycles. The evolutions of the bond properties were monitored by performing double lap shear tests at periodic intervals, while changes in the mechanical properties of the weakest constituent materials, namely the bulk polymer adhesive and the concrete, were investigated by means of tensile and compressive tests respectively. A new geometry of double-shear test specimens is proposed, which restricts the possible variation of the effective transfer length that may compensate the decrease in the mechanical properties of the polymer adhesive during ageing. In this way, it is ensured that the double shear test is actually sensitive to variations in the adhesive properties. It is to note that in a previous study [9] carried-out on concrete samples strengthened with the same CFRP systems as in this research and involving an ageing condition similar to that found in the climatic chamber 1, authors reported that no evolution of the shear capacity was observed after 1 year of ageing for specimens designed with a 200mm FRP bonded length. With the proposed new geometry of sample (with small bonded length), it was possible to observe a 
slight decrease in the average shear strength during the first 8 months of samples stored in CC1. From the authors' point of view, this result justifies the proposed experimental procedure.

The results of the mechanical tests carried out over the 12-month ageing period show that

- Only small reductions in tensile strength were observed for bulk adhesive samples exposed to freezethaw and hygric cycles (residual strengths were respectively $95 \%$ and $91 \%$, with respect to initial strength).

- After a first period of tensile strength loss (roughly during the first two months of ageing), a partial recovery was observed for bulk adhesive samples subjected to constant humidity conditions (95\% R.H., at $40^{\circ} \mathrm{C}$ ). At the end of the 12 -month ageing period in these conditions, a residual tensile strength of $72 \%$ was measured.

- Trends observed for evolutions of the tensile strength of bulk adhesive samples seem highly correlated to water absorption: the higher the moisture uptake, the higher the reduction in tensile strength. Moreover, the curves describing moisture absorption and strength loss exhibit almost identical twoperiod evolutions with reversible behaviors (even if the duration of periods was different). In accordance with previous studies, such a behavior can be explained by a competition between 2 antagonistic phenomena, i.e. a plasticization of the adhesive driven by moisture ingress, and a crosslinking mechanism due to the reaction of residual monomers which becomes more predominant when the sorption process reaches saturation.

- Whatever the ageing condition, only a limited reduction in the average shear strength was observed for bonded assemblies at the end of the 12-month ageing period (residual values of $89 \%, 87 \%$ and $85 \%$ with respect to initial bond properties, after exposure to constant humidity, freeze-thaw cycles and hygric cycles, respectively). However, a higher loss of the shear capacity was observed under constant humidity at intermediate period (roughly, after 8 months), suggesting that prolonged exposure to moisture is the most detrimental condition. Nevertheless, a partial recovery is also observed in the long term, which can be attributed to a crosslinking mechanism similar to that evidenced for the bulk adhesive samples.

- For double shear specimens subjected to constant humidity conditions, deterioration mechanisms related to moisture ingress in the epoxy network / at interfaces are complex and result in multiple failure 
modes, as evidenced by the analysis of the fracture patterns on tested samples. Differently, concrete failure remains the predominant failure mode on the fractured surfaces of specimens subjected to the other ageing conditions.

\section{References}

[1] Meier, U., and Kaiser, H.-P., "Strengthening of structure with CFRP laminates," ASCE specialty conference Advanced composite materials in civil engineering structures, S. L. Iyer, and R. Sen, Eds., Las Vegas, NV. 1991.

[2] Fib, "Externally bonded FRP reinforcement for RC structures," Fédération Internationale du Béton fib-Bulletin 14, Lausanne, Switzerland, 2001.

[3] National Research Council, CNR-DT 200/2004 "Guide for the design and construction of externally bonded FRP systems for strengthening existing structures," 2004.

[4] ACI Committee 440.2R-08 "Guide for the Design and Construction of Externally Bonded FRP Systems for Strengthening Concrete Structures,”2008.

[5] AFGC, "Réparation et renforcement des structures en béton au moyen des matériaux composites. Recommandations provisoires," Bulletin scientifique et technique de l'Association française de génie civil (in french), 2011.

[6] Sen, R., "Developments in the durability of FRP-concrete bond," Constr Build Mater, Vol. 78, 2015, pp. 112-125.

[7] Chu, W., Wu, L., and Karbhari, V. M., "Durability evaluation of moderate temperature cured E-glass/vinylester systems," Compos. Struct., Vol. 66, 2004, pp. 367-376.

[8] Abanilla, M. A., Li, Y., and Karbhari, V. M., "Durability characterization of wet layup graphite/epoxy composites used in external strengthening," Compos. Part B: Eng., Vol. 37, No. 2, 2005, pp. 200-212.

[9] Benzarti, K., Chataigner, S., Quiertant, M., Marty, C., and Aubagnac, C., “Accelerated ageing behaviour of the adhesive bond between concrete specimens and CFRP overlays," Constr Build Mater, Vol. 25, No. 2, Sp. Iss, 2011, pp. 523-538.

[10] Sen, R., "Developments in the durability of FRP-concrete bond," Constr Build Mater, Vol. 78, 2015, pp. 112-125.

[11] Pan, Y., Xian, G., and Silva, M. A. G., "Effects of water immersion on the bond behavior between CFRP plates and concrete substrate," Constr Build Mater, Vol. 101, 2015, pp. 326-337. 
[12] Quiertant, M., Benzarti, K., Landrin, F., Landrin, M., Schneider, J., Boinski, F., "Durability of FRP to concrete bonded interface under accelerated ageing” 8th RILEM International Conference on Mechanisms of Cracking and Debonding in Pavements, A. Chabot, W.G., Buttlar, E.V., Dave, C., Petit, G. Tebaldi, Eds., Springer Netherlands, 2016, pp. 605-611.

[13] Lau, D., and Büyüköztürk, O., "Fracture characterization of concrete/epoxy interface affected by moisture," Mechanics of Materials, Vol. 42, 2010, pp. 1031-1042.

[14] Shrestha, J., Ueda, T., and Zhang, D. "Durability of FRP Concrete Bonds and Its Constituent Properties under the Influence of Moisture Conditions," J. Mater. Civ. Eng., Vol. 27, No. 2, 2015, A4014009

[15] Yun, Y., and Wu, Y.-F., "Durability of CFRP-concrete joints under freeze-thaw cycling," Cold Reg. Sci. Technol., Vol. 65, 2011, pp. 401-412.

[16] Karbhari, V.M., and Engineer, M., "Investigation of bond between concrete and composites: use of a peel test," $J$. Reinforced Plast. Compos., Vol. 15, No 2, 1996, pp. 208-227.

[17] Davalos, J.F., Kodkani, S.S., Ray, I., and Boyajian, D.M., 2005. "A fracture mechanic approach for interface durability of bonded FRP to concrete," presented at the 7th Int. Symp. on FRP Reinforcement for R.C. Structures (FRPRCS-7). ACI, Kansas City, Kan, USA, pp. 1465-1479.

[18] Kolluru, V., Ali-Ahmad, M., and Ghosn, M., "Freeze-thaw degradation of FRP-concrete interface: impact on cohesive fracture response," Eng. Fract. Mech., Vol. 75, 2008, pp. 3924-3940.

[19] Green, M.F., Soudki, K.A., and Johnson, M.M., "Freeze-thaw behaviour of reinforce concrete beams strengthened by fibre reinforced plastic sheets,” Proc. Canadian Soci. Civ. Eng., Sherbrooke. 27-30 May 1997.

[20] Mukhopadhyaya, P., Swamy, R.N., and Lynsdale, C.J., "Influence of aggressive exposure conditions on the behaviour of adhesive bonded concrete-GFRP joints," Constr. Build. Mater., Vol. 18, No 12, 1998, pp. 427-446.

[21] Green, M.F., Bisby, L.A., Beaudoin, Y., and Labossiere, P., "Effect of freeze-thaw cycles on the bond durability between fibre reinforced polymer plate reinforcement and concrete," Can. J. Civ. Eng., Vol. 27, 2000, pp. 949-959.

[22] Bisby, L.A., and Green, M.F., "Resistance to freezing and thawing of fiber-reinforced polymer-concrete bond," ACI Struct. J. Vol. 99, No 2, 2002, pp. 215-223.

[23] Pavel, D., "Environmental durability of FRP bond to concrete subjected to freeze-thaw action," M. Phil. thesis, Massachusetts Institute of Technology, 2006.

[24] Yao, J., Teng, J.G., and Chen, J.F., "Experimental study on FRP-to-concrete bonded joints,” Compos. Part B: Eng., Vol. 36, No. 2, 2005, pp. 99-113.

[25] Leone, M., Matthys, S., and Aiello, M-A., "Effect of elevated service temperature on bond between FRP EBR systems and concrete," Compos. Part B, Vol. 40, No. 1, 2009, pp. 85-93. 
[26] Serbescu, A., Guadagnini, M., and Pilakoutas, K., "Standardised double-shear test for determining bond of FRP to concrete and corresponding model development" Compos. Part B, Vol. 55, 2013, pp. 277-297.

[27] Ferrier, E., Quiertant, M., Benzarti, K., and Hamelin, P., "Influence of the properties of externally bonded CFRP on the shear behavior of concrete/composite adhesive joints," Compos. Part B: Eng., Vol 41, No. 5, 2010, pp. 354362.

[28] Japanese Concrete Institute. Report II of research committee on continuous fiber-reinforced concrete, vol. 5, 1998.

[29] Aydin, H., Gravina, R. J., and Visintin, P., “Durability of Adhesively Bonded FRP-to-Concrete Joints,” J. Compos. Constr., Vol. 20, No 5, 2016, 04016016

[30] Sika Corporation US Sika CarboDur ${ }^{\circledR}$ Carbon fiber laminate for structural strengthening. Product Data Sheet Edition 5.4. 2011.

[31] SIKA Distributor Sikadur ${ }^{\circledR} 30$ High-modulus, high-strength, structural epoxy paste adhesive for use with Sika ${ }$ CarboDur® reinforcement.

[32] CSTB, Avis $\quad$ Technique $\quad 3 / 10-669$ Sika $\quad$ CarboDur ${ }^{\circledR} \quad$ SikaWrap ${ }^{\circledR} \quad 026$, Available from: https://archive.org/details/22FrAtSikaCarbodurSikaWrap

[33] Chataigner, S., Caron, J.-F., Benzarti, K., Quiertant, M., and Aubagnac, C., "Characterization of composite to concrete bonded interface. Description of the single lap shear test," Eur J Environ Civil Eng, Vol. 13, No 9, 2009, pp. 1073-1082.

[34] Chataigner, S., Caron, J.-F., Benzarti, K., Quiertant, M., and Aubagnac, C., "Use of a single lap shear test to characterize composite-to-concrete or composite-to-steel bonded interfaces.” Constr Build Mater, Vol. 25, No. 2, Sp. Iss, 2011, pp. 468-478.

[35] Shaw, S. J., Epoxy resin adhesives. In: Ellis B, editor. Chemistry and technology of epoxy resins. London: Blackie Academic \& Professional 1994. p. 206-55.

[36] Frigione, M., Aiello, M. A., and Naddeo, C., "Water effects on the bond strength of concrete/concrete adhesive joints," Constr. Build. Mater., Vol. 20, 2006, pp. 957-970.

[37] Zhou, J., and Lucas, J.-P., "Hygrothermal effects of epoxy resins. Part I: the nature of water in epoxy," Polymer, 1999, Vol. 40, 1999, pp. 5505-5512. 


\section{List of figure captions}

Fig. 1 Principle of the near-end supported double-shear test: a) Double lap-joint shear test specimen, b) Schematic description of the loading conditions (reprinted from [12])

Fig. 2 Test of different specimen geometries with a steel rod embedded in concrete prisms.

Fig. 3 Fixture device designed for the reduced-size shear specimens.

Fig. 4. Test setup for the double lap shear experiments (reprinted from [12]).

Fig. 5. Concrete blocks after removal from the formworks (reprinted from [12]).

Fig. 6: Geometry of the FRP-strengthened concrete specimens (dimensions are in mm - reprinted from [12]).

Fig. 7 Storage of concrete cylinders, dumbbell shaped adhesive specimens and double-shear samples submitted to the same ageing condition.

Fig. 8 Preparation of dumbbell shaped adhesive specimens.

Fig. 9 Description of ageing cycles in a) Climatic chamber $\mathrm{N}^{\circ} 2$, and b) Climatic chamber $\mathrm{N}^{\circ} 3$ (reprinted from [12]).

Fig. 10 Time evolution of the compressive strength of the concrete cylinders exposed to various ageing conditions.

Fig. 11 Time evolution of the tensile strength of the epoxy specimens exposed to various ageing conditions.

Fig. 12 Moisture-absorption (in weight \%) of bulk adhesive samples exposed to the various ageing conditions.

Fig. 13 Time evolutions of the average shear strength for specimens exposed to the various environments.

Fig. 14 Example of cohesive failure in concrete.

Fig. 15 Example of mixed failure mode (20\% adhesive failure at the epoxy/concrete interface and $80 \%$ adhesive failure at the epoxy/FRP interface).

Fig. 16 Analysis of the fractured surfaces of double shear specimens after exposure in CC1: quantitative evaluation of the relative surface areas for the five types of failure modes.

Fig. 17 Analysis of the fractured surfaces of double shear specimens after exposure in CC2: quantitative evaluation of the relative surface areas for the five types of failure modes.

Fig. 18 Analysis of the fractured surfaces of double shear specimens after exposure in CC3: quantitative evaluation of the relative surface areas for the five types of failure modes. 
2

\section{List of figures}
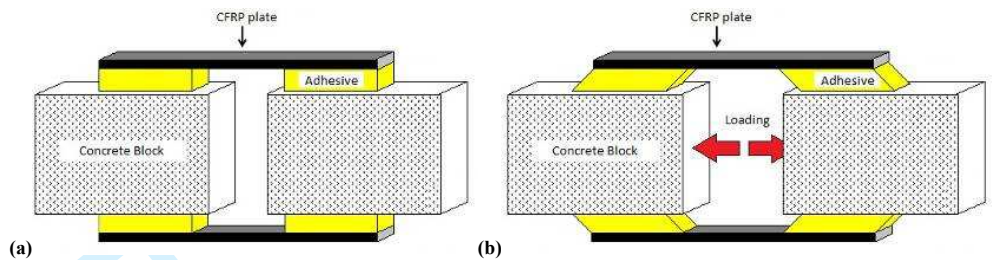

Fig. 1 Principle of the near-end supported double-shear test: a) Double lap-joint shear test specimen, b)

Schematic description of the loading conditions (reprinted from [12])

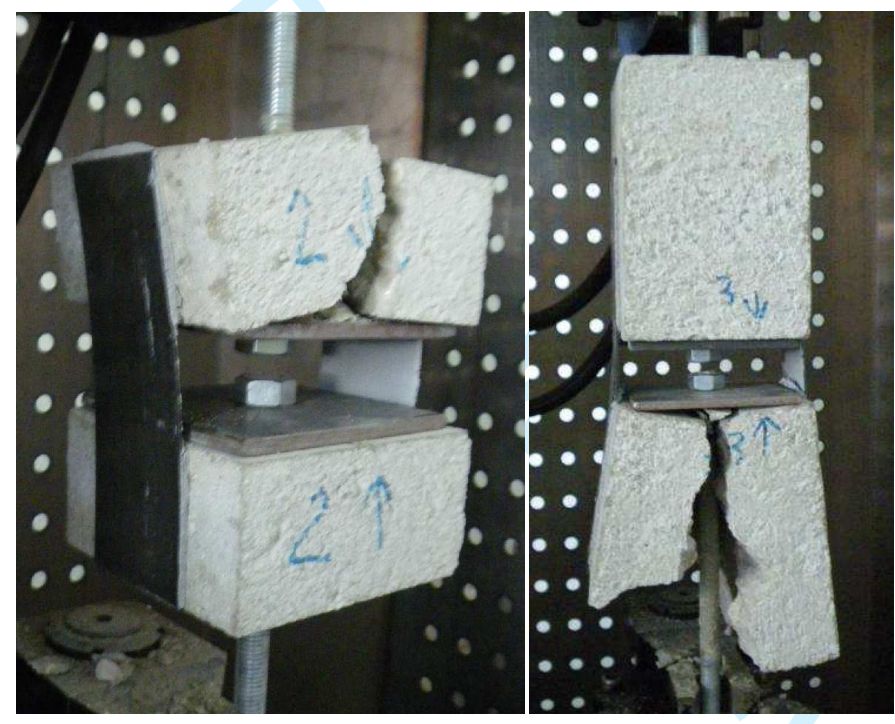

Fig. 2 Test of different specimen geometries with a steel rod embedded in concrete prisms.

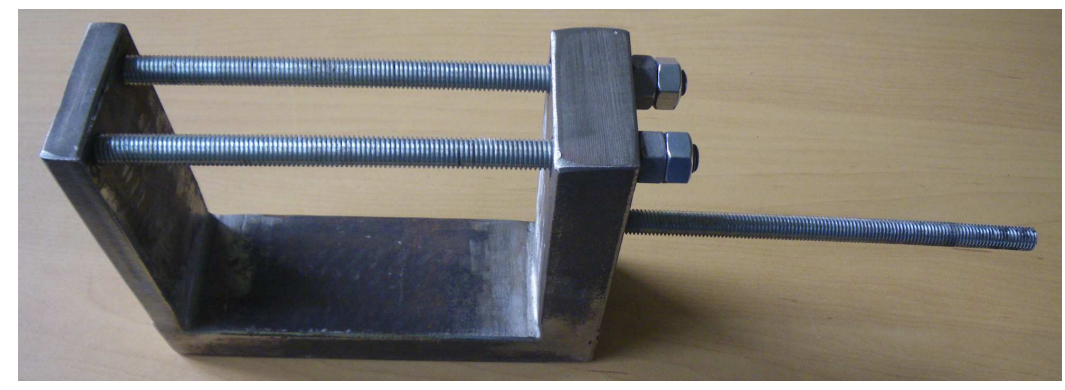

Fig. 3 Fixture device designed for the reduced-size shear specimens. 


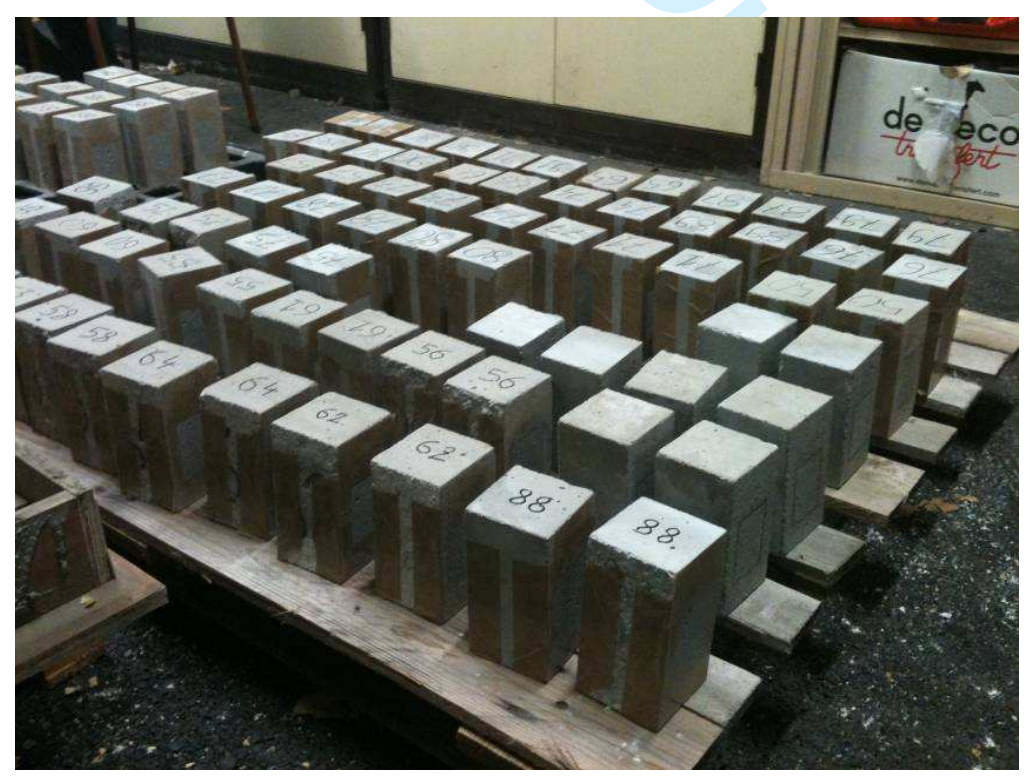

Fig. 4. Test setup for the double lap shear experiments (reprinted from [12]).

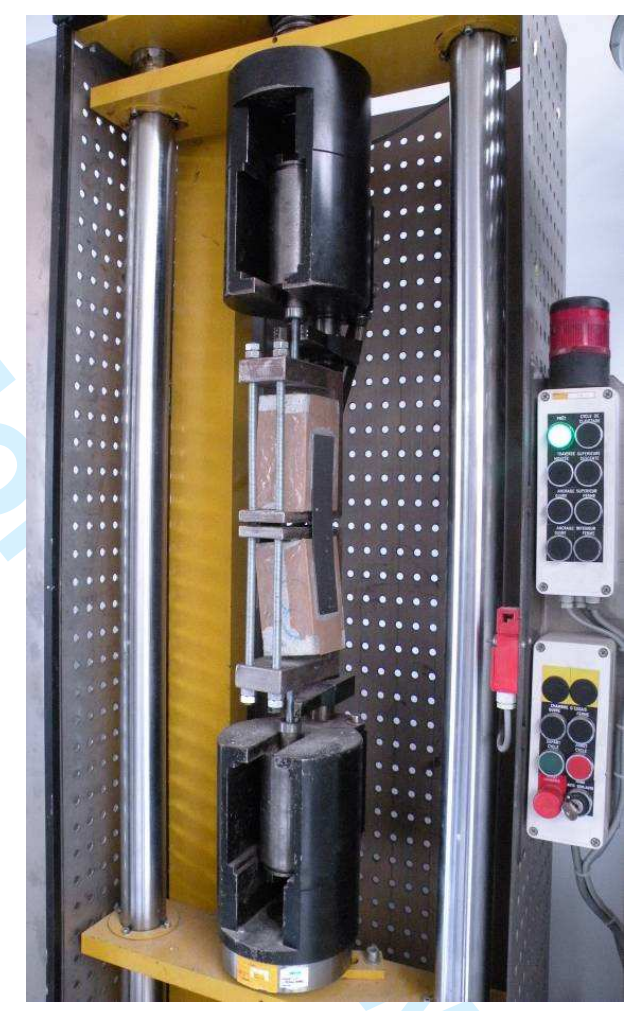

Fig. 5. Concrete blocks after removal from the formworks (reprinted from [12]). 


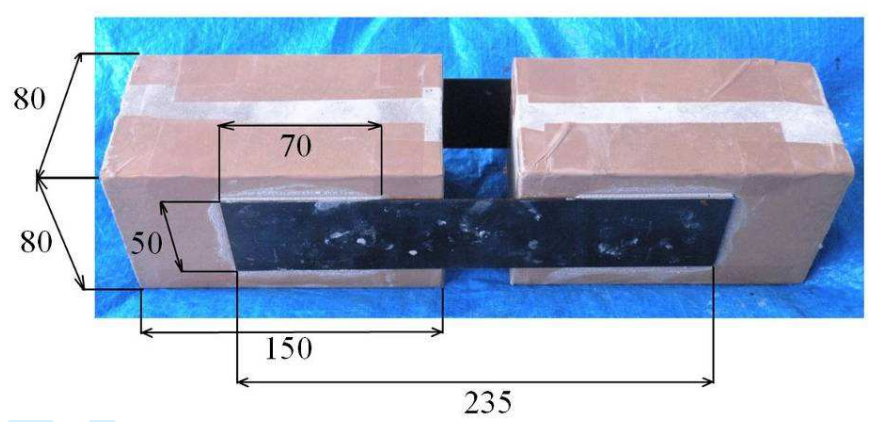

Fig. 6: Geometry of the FRP-strengthened concrete specimens (dimensions are in mm - reprinted from [12]).

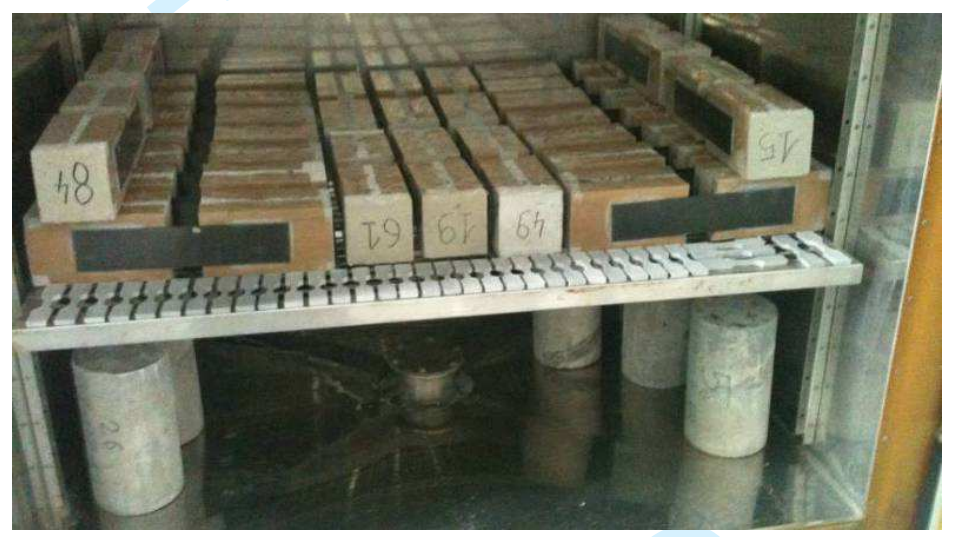

Fig. 7: Storage of concrete cylinders, dumbbell shaped adhesive specimens and double-shear samples submitted to the same ageing condition.

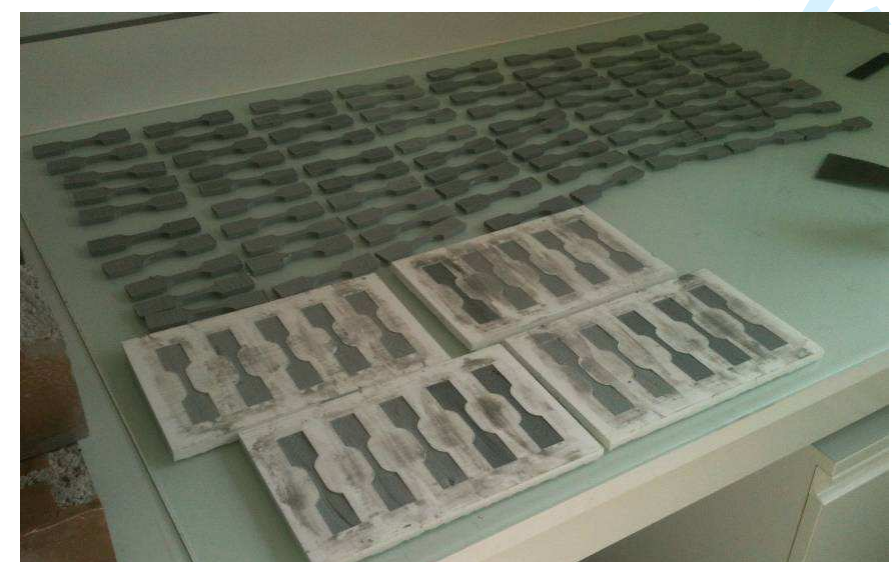

Fig. 8 Preparation of dumbbell shaped adhesive specimens. 
Fig. 9 Description of ageing cycles in a) Climatic chamber $\mathrm{N}^{\circ} 2$, and b) Climatic chamber $\mathrm{N}^{\circ} 3$ (reprinted from [12]).

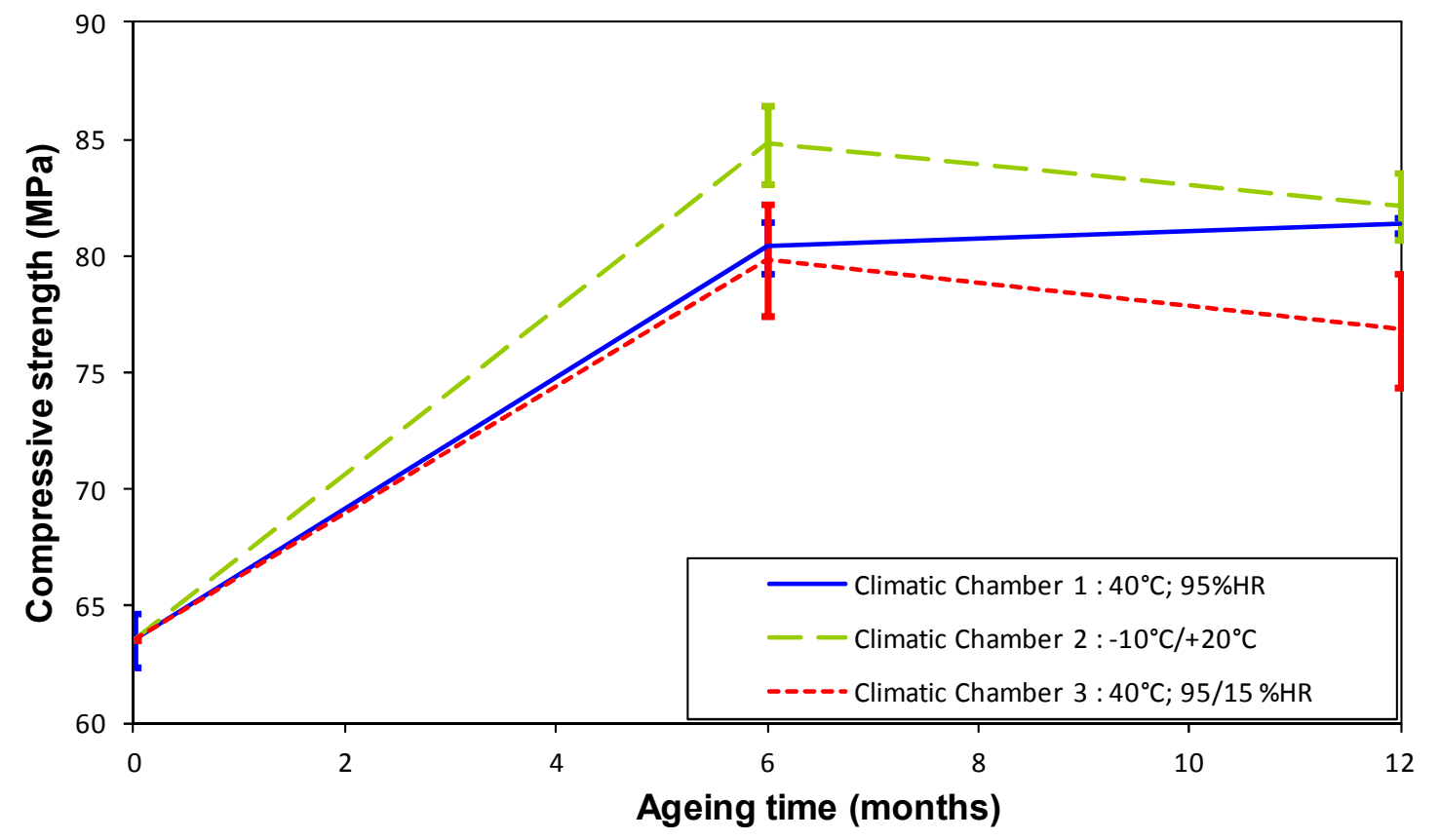

Fig. 10 Time evolution of the compressive strength of the concrete cylinders exposed to various ageing conditions. 


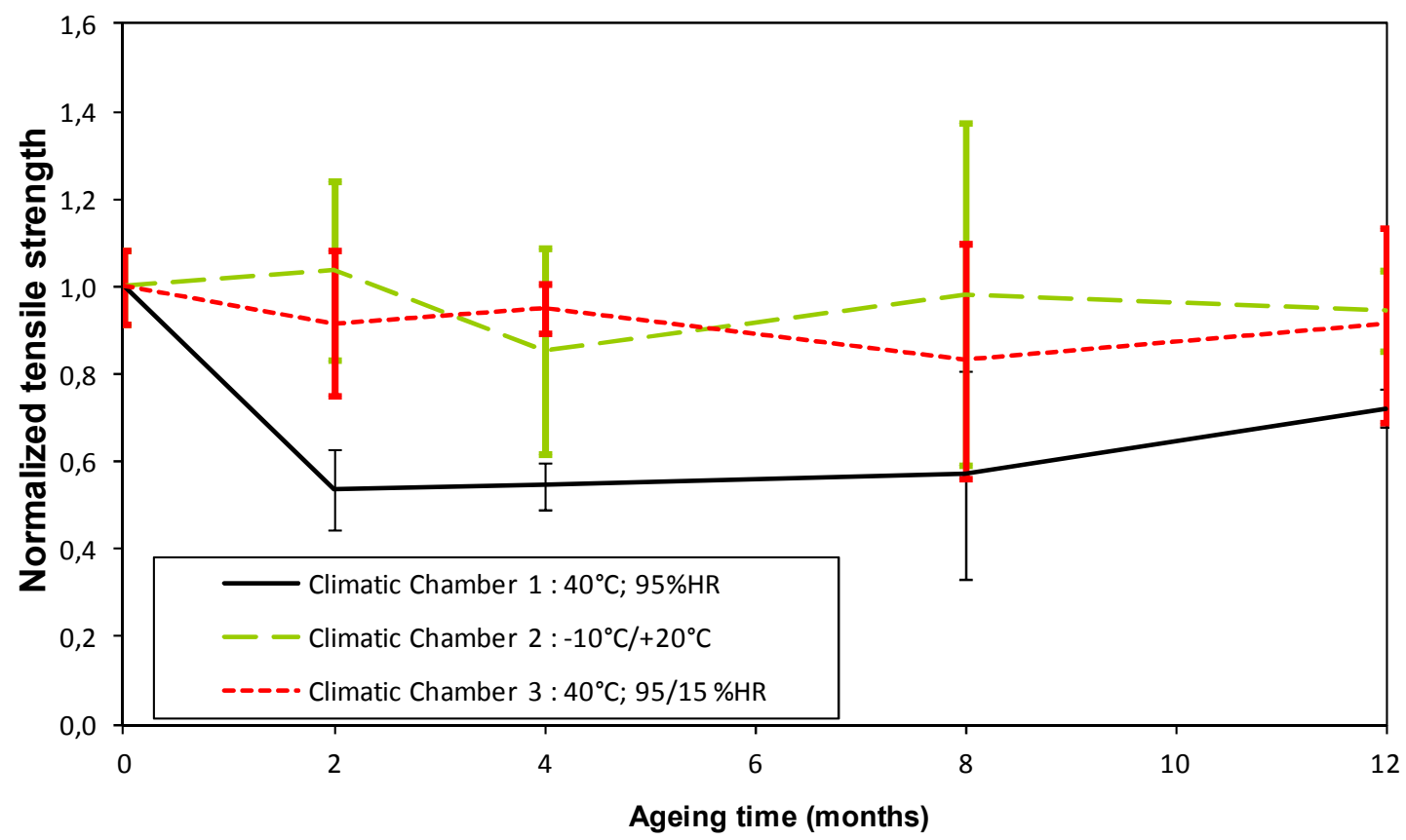

Fig. 11 Time evolution of the tensile strength of the epoxy specimens exposed to various ageing conditions.

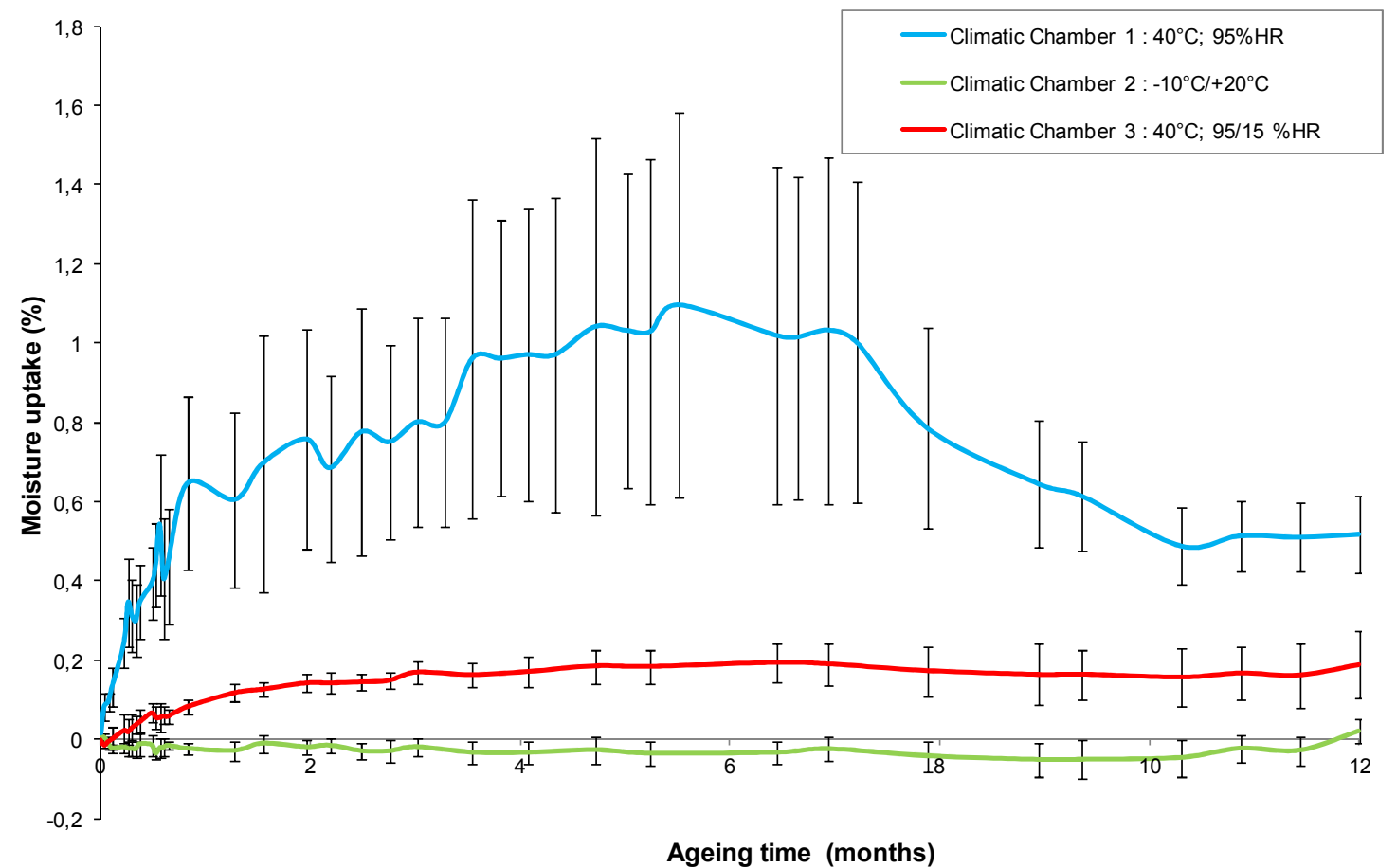

Fig. 12 Moisture-absorption (in weight \%) of bulk adhesive samples exposed to the various ageing conditions. 

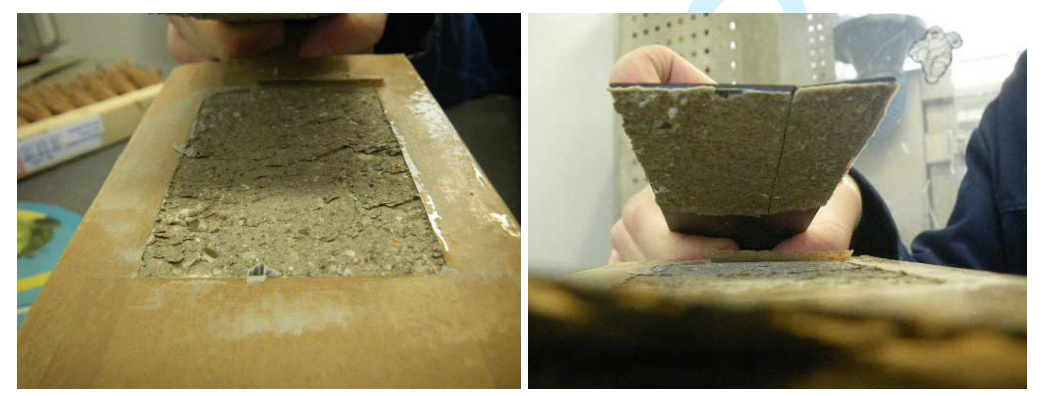

Fig. 14 Example of cohesive failure in concrete.

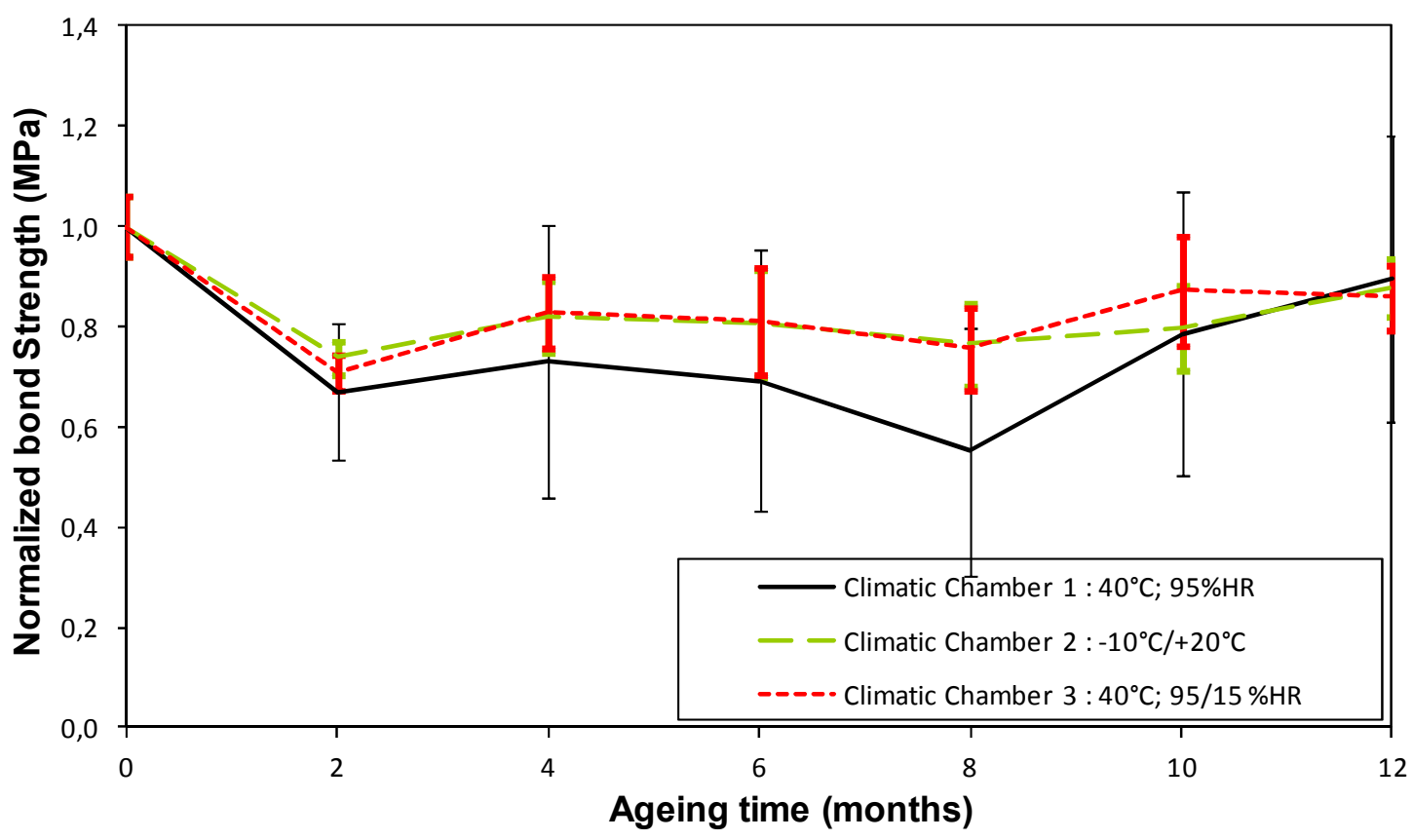

Fig. 13 Time evolutions of the average shear strength for specimens exposed to the various environments. 
8

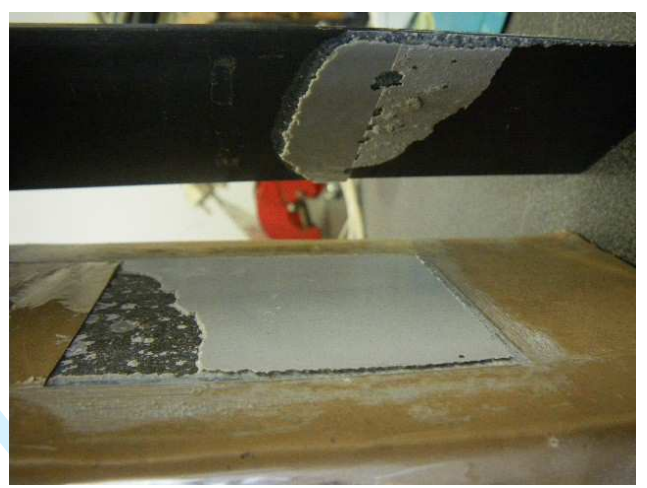

Fig. 15 Example of mixed failure mode (20\% adhesive failure at the epoxy/concrete interface and $80 \%$ adhesive failure at the epoxy/FRP interface).

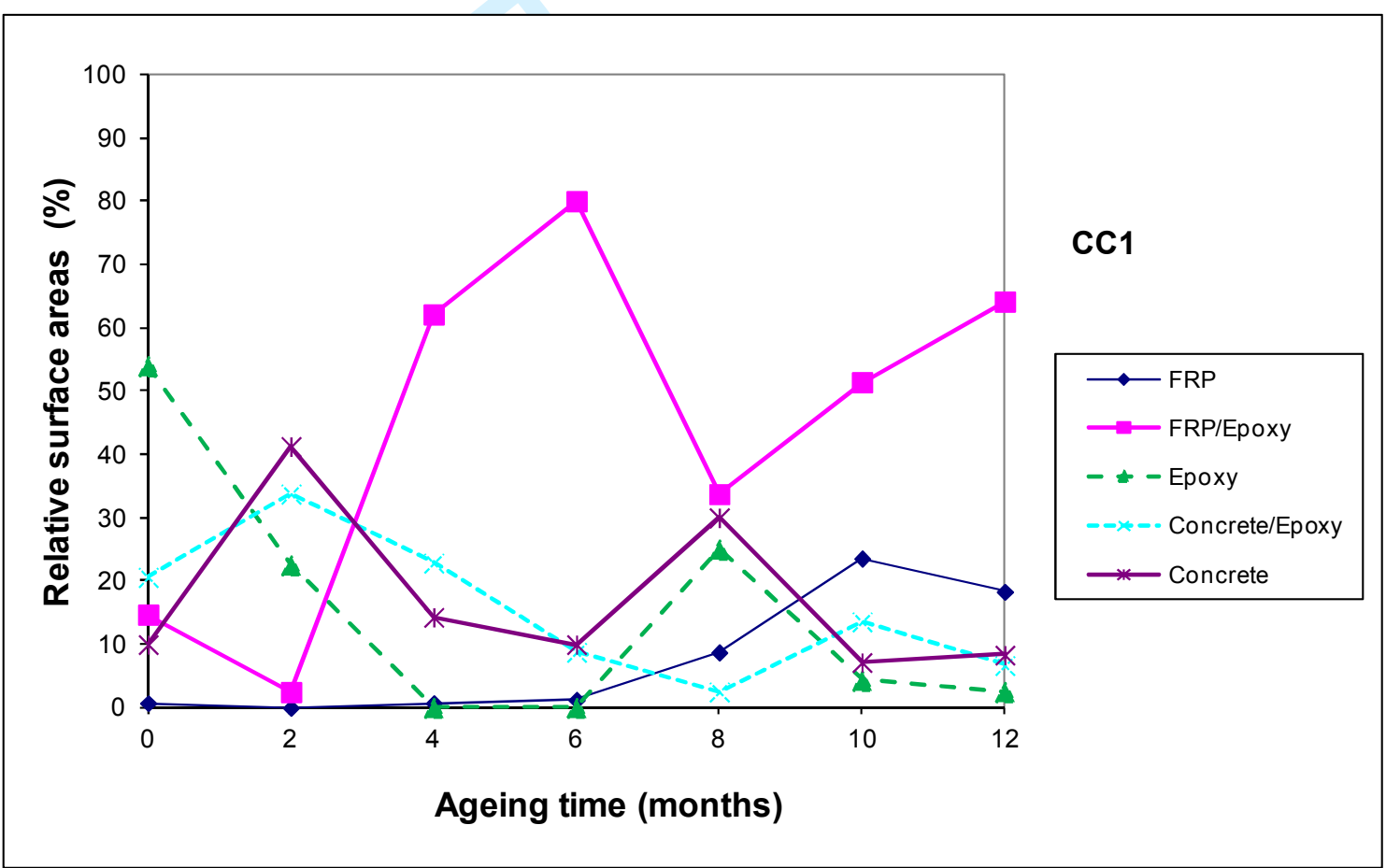

Fig. 16 Analysis of the fractured surfaces of double shear specimens after exposure in $\mathrm{CC} 1$ : quantitative evaluation of the relative surface areas for the five types of failure modes. 
Fig. 17 Analysis of the fractured surfaces of double shear specimens after exposure in CC2: quantitative evaluation of the relative surface areas for the five types of failure modes. 
10

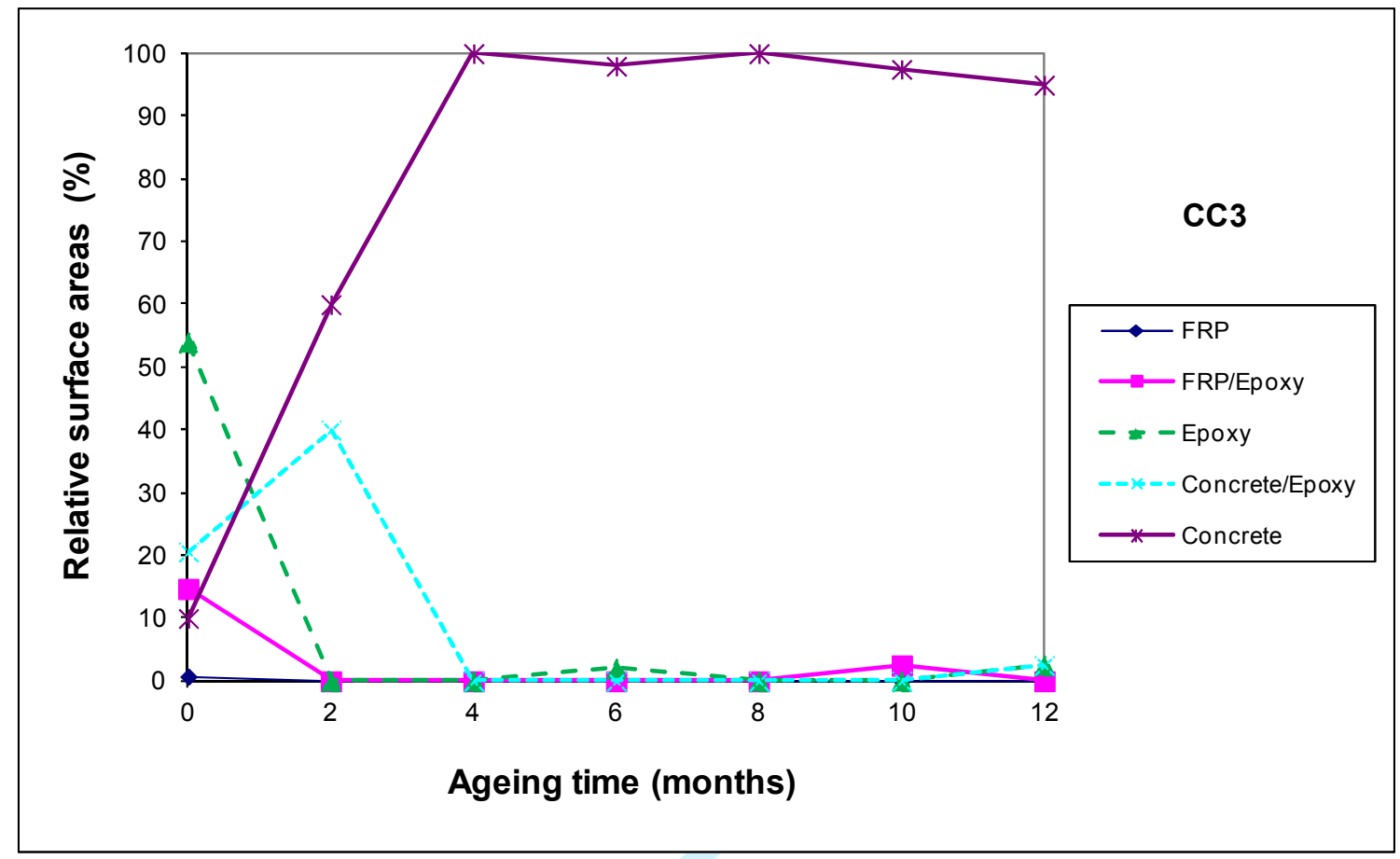

Fig. 18 Analysis of the fractured surfaces of double shear specimens after exposure in CC3: quantitative evaluation of the relative surface areas for the five types of failure modes. 
1

2

3

4

5

6

7

8

9

10

11

12

13

14

15

16

17

18

19

20

21

22

23

24

25

26

27

28

29

30

31

32

33

34

35

36

37

38

39

40

41

42

43

44

45

46

47

48

49

50

51

52

53

54

55

56

57

58

59

60
List of table captions

Table 1: Experimental program 
12

List of tables

Table 1: Experimental program

\begin{tabular}{|c|c|c|c|c|c|c|c|}
\hline & & \multicolumn{6}{|c|}{$\begin{array}{l}\text { Initial characterization } \\
\text { Number of tested samples }\end{array}$} \\
\hline & Compression test on concrete cylinders & \multicolumn{6}{|c|}{4} \\
\hline & Shear test on FRP-strengthened concrete specimens & \multicolumn{6}{|c|}{12} \\
\hline & Tensile strength of the epoxy specimens & \multicolumn{6}{|c|}{6} \\
\hline & & \multicolumn{6}{|c|}{ Ageing time (months) } \\
\hline & & 2 & 4 & 6 & 8 & 10 & 12 \\
\hline & & \multicolumn{6}{|c|}{ Number of tested samples } \\
\hline \multirow{3}{*}{$\begin{array}{l}\text { Climatic Chamber } 1 \text { : } \\
40^{\circ} \mathrm{C} ; 95 \% \mathrm{HR}\end{array}$} & Compression test on concrete cylinders & $\mathrm{x}$ & $\mathrm{x}$ & 4 & $\mathrm{X}$ & $\mathrm{x}$ & 4 \\
\hline & Shear test on FRP-strengthened concrete specimens & 4 & 4 & 4 & 4 & 4 & 4 \\
\hline & Tensile strength of the epoxy specimens & 6 & 6 & 6 & 6 & 6 & 6 \\
\hline \multirow{3}{*}{$\begin{array}{l}\text { Climatic Chamber } 2 \text { : } \\
-10^{\circ} \mathrm{C} /+20^{\circ} \mathrm{C}\end{array}$} & Compression test on concrete cylinders & $\mathrm{x}$ & $\mathrm{x}$ & 4 & $\mathrm{x}$ & $\mathrm{x}$ & 4 \\
\hline & Shear test on FRP-strengthened concrete specimens & 4 & 4 & 4 & 4 & 4 & 4 \\
\hline & Tensile strength of the epoxy specimens & 6 & 6 & 6 & 6 & 6 & 6 \\
\hline \multirow{3}{*}{$\begin{array}{l}\text { Climatic Chamber } 3 \text { : } \\
40^{\circ} \mathrm{C} ; 95 / 15 \% \mathrm{HR}\end{array}$} & Compression test on concrete cylinders & $\mathrm{X}$ & $\mathrm{X}$ & 4 & $\mathrm{X}$ & $\mathrm{x}$ & 4 \\
\hline & Shear test on FRP-strengthened concrete specimens & 4 & 4 & 4 & 4 & 4 & 4 \\
\hline & Tensile strength of the epoxy specimens & 6 & 6 & 6 & 6 & 6 & 6 \\
\hline
\end{tabular}

